\title{
Burnout syndrome and wellbeing in anesthesiologists: the importance of emotion regulation strategies
}

\author{
Teresa A. LAPA ${ }^{1,2}{ }^{*}$, Filipa M. MADEIRA ${ }^{1}$, Joaquim S. VIANA ${ }^{2}$, José PINTO-GOUVEIA ${ }^{3}$ \\ ${ }^{1}$ Coimbra Hospital and University Centre, Coimbra, Portugal; ${ }^{2}$ Faculty of Health Sciences, University of Beira \\ Interior, Covilhã, Portugal; ${ }^{3}$ Cognitive-Behavioral Research Center (CINEICC), University of Coimbra, Coimbra, \\ Portugal \\ *Corresponding author: Teresa A. Lapa, Anesthesiology Service, Coimbra Hospital and University Centre, Praceta Prof. Mota Pinto, \\ 3000-075 Coimbra, Portugal. E-mail: teresalapa@hotmail.com
}

\begin{abstract}
ABSTR A C T
Anesthesiologists face stressful working conditions that can culminate in burnout syndrome. Despite various studies and protective measures which have attempted to prevent this situation, burnout continues to be a problem within the profession, impacting negatively on physicians' lives and their performance. In this review article mechanisms and consequences of burnout are described in addition to individual strategies for stress management and burnout reduction with potential impact on health care quality and wellbeing in anesthesiologists. Organizational strategies appear to have an important role in burnout reduction but need to be used in conjunction with individual programs. The latter are essential to both reducing stress and burnout in anesthesiologists and improving happiness and wellbeing. New measures of emotion regulation strategies such as mindfulness, self-compassion, resilience and empathy promotion have been shown to be approaches with substantial supporting evidence for reducing burnout and improving stress management. The evaluation and implementation of these self-regulatory competencies is a challenge. Further research is necessary to identify which programs will best suit the needs of anesthesiologists and to measure their effects on patient care and health care system quality.

(Cite this article as: Lapa TA, Madeira FM, Viana JS, Pinto-Gouveia J. Burnout syndrome and wellbeing in anesthesiologists: the importance of emotion regulation strategies. Minerva Anestesiol 2017;83:191-9. DOI: 10.23736/S0375-9393.16.11379-3) Key words: Anesthesiology - Professional burnout - Psychological stress - Emotions.
\end{abstract}

$66 T^{t}$ Tt is not what happens to you, but how you react to it that matters" - this wellknown quote of the Greek Epictetus (55-135 AD) is frequently forgotten when dealing with the subject of burnout. The individual mechanisms involved in response to external factors are essential to whether stress with potential to produce burnout causes harm or not.

Burnout is defined as a psychological phenomenon of continued exposure to work re-

Comment in p. 136. lated stressors. According to Maslach et al.,1 burnout is the process by which an employee's psychological resources are depleted due to prolonged stress at work. Symptoms consist of feeling emotionally depleted and cynical towards co-workers and patients in addition to feeling that they are not completing their tasks successfully. It is a matter of debate whether burnout is a form of depression or a distinct phenomenon. ${ }^{2}$ It is usually considered to be a specific job-related problem whereas depression, being non-specif- 


\section{COPYRIGHT ${ }^{\odot} 2017$ EDIZIONI MINERVA MEDICA}

LAPA

BURNOUT SYNDROME AND EMOTION REGULATION

ic in its nature, can develop outside of the workplace.

Burnout continues to be a field of interest amongst anesthesiologists, ${ }^{3}$ and according to some studies, it has been growing considerably. ${ }^{4}$ However, in a specialty where quality and security are paramount it is alarming that its prevalence remains a problem..$^{5-7}$ Physician health and wellness is an extremely complex topic that is relevant to anesthesiologists at all stages of their careers. Like all medical areas, anesthesia is thought to have become safer for patients but more dangerous for physicians. ${ }^{8}$ The work of an anesthesiologist is taxing due to a high array of demands, stressful situations and the need to be ready and alert for long periods of time. Continued exposure to these elements can culminate in a burnout situation, a process that leads to the loss of physical and mental energy.

Many of the sources of stress in anesthesia are well characterized,5, 6, 9, 10 but the way they are interpreted and reacted to and how they lead to the development of burnout has not been clarified yet. The study of personal/ individual traits related to emotion regulation can be important in clarifying burnout mechanisms and promoting strategies to deal with this problem.

\section{Burnout mechanisms}

The mechanisms by which stress and burnout manifest themselves as a consequence of the work situation are unclear. ${ }^{11,12}$

A synchronized set of endocrine, immunological, autonomic, behavioral, cognitive and emotional responses to perceived threats characterizes stress response. There appears to be a clear link between the dysfunction of these mechanisms due to chronic stress and pathologic responses. Identification of these mechanisms can lead to strategies for prevention and treatment.

No biological markers of burnout have been found yet, despite several biomarkers having been tested for association. ${ }^{2,} 13$ Growing evidence suggests that burnout may be associated with distinct alterations in the hypothalamic- pituitary-adrenal axis production of cortisol. 2,13

Recent studies suggest that dysfunction of stress response mediators as a consequence of chronic stress leads to stress related pathology. There are different convergent points in the brain for opioid/CRF (corticotropin-releasing factor) interaction, especially locus coeruleus (LC) and dorsal raphe nucleus, ${ }^{14}$ in which an altered balance between the "pro-" and "antistress" systems occur. Endogenous neuromediators including opioids have been proposed to give protection against the effect of "prostress" mediator, CRF. ${ }^{15}$ CRF is a brain neuromodulator that coordinates autonomic, behavioral and cognitive responses to stress and is considered the hypothalamic orchestrator of the stress response (Figure 1). ${ }^{15}$

Vulnerability to the pathological consequences of stress can be determined by innate individual differences in endogenous mechanisms that oppose the stress response. This variability may result from differences in enkephalin expression, opioid receptors sensitivity or polymorphisms. ${ }^{16}$ It is known that females have a decreased MOR ( $\mu$-opioid receptor) sensitivity, ${ }^{17}$ which would be consistent with reports stating that stress-related diseases are more prevalent in women. Beyond

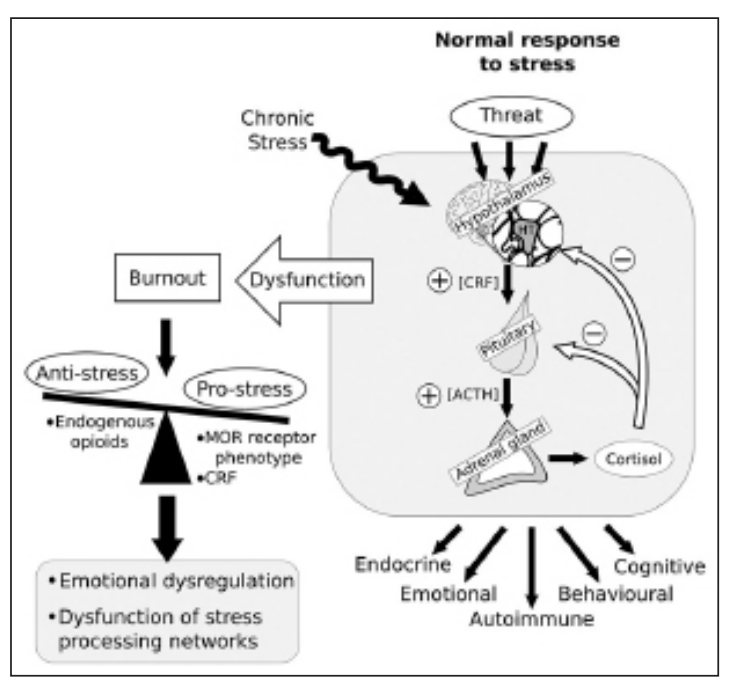

Figure 1.-Burnout mechanisms.

CRH: corticotropin-releasing factor; ACTH: adrenocorticotropic hormone; MOR: $\mu$-opioid receptor. 


\section{COPYRIGHT ${ }^{\odot} 2017$ EDIZIONI MINERVA MEDICA}

this, it has been suggested that age-related individual differences are also related to developmental differences in enkephalin-MOR system. ${ }^{16}$

Several behavioral studies have found a relation between burnout and weakened emotional regulation and Tei et al. ${ }^{18}$ suggest that burnout in physicians may be due to reduced empathy-related brain activity. Golkar et al. ${ }^{12}$ (2014) have found by functional magnetic resonance imaging studies that individuals who suffered from chronic occupational stress were less able to modulate emotion and stress-processing networks. This supports the notion that burnout is a condition that is related to limbic system affection. An impairment of the ability to down-regulate negative emotions may make them more likely to suffer. The widespread use of brain imaging studies has shown the potential to predict burnout 18 and their association with psychological exams can help to understand this phenomenon.

\section{Burnout risk factors}

Burnout has become a prominent topic of research within the community of anesthesiologists. Multiple studies on job stress and burnout in anesthesia have been developed trying to identify the main stressors in anesthesia and risk factors for burnout development.

Social and work environment factors are important but personal variability appears to be as important and explains why different physicians within the same work environment react differently. These personal factors may be components of emotional regulation, genetically determined or not. We already have plenty of knowledge with regard to social factors and work environment, ${ }^{9}$ but where individual characteristics are concerned there is a long and challenging task ahead. Furthermore, the interplay between each anesthesiologist and their environment is highly influential in the development of burnout.

Table I summarizes stress and burnout risk factors that are potential threats to physician wellness.
TABLE I.-The epidemiology of stress and burnout: risk factors.

Physician-related factors

- Female gender 7,19

- Residents and young specialists 6,7

- Suboptimum attention to self-wellness by physicians 20

- Emotional profile and predisposing traits (perfectionism, neuroticism, workaholism) 3,21

- Difficult relationships with patients, their families and other medical staff 19

- Anesthesiologist-surgeon conflicts 22

- Genetic factors 23

- Difficulty balancing personal and professional life 7

Work-related environmental and organizational factors

- Excessive workload / production pressure / sleep deprivation 1,20,24

- Poor work organization 19

- Lack of clinical autonomy/lack of recognition 1,19

- Emotional interactions (deal with death and suffering) 5,6

- Poor leadership / lack of supervision 5

- Non-reciprocal relationship that anesthesiologists have with their patients 5

- Presence of non- skilled assistance in the operating theatre 19

- Physical environment (noise, air quality, toxic exposure)

- Community hospitals vs. academic hospitals 5

- On call work and work in emergency 25

- Excessive administrative tasks 26

- Work in large size teams ${ }^{7}$

\section{Consequences of burnout}

Burnout has been increasingly recognized as a burden for society as a whole. When physicians are dissatisfied the quality of health care systems is under threat. It is not only the wellbeing of the clinicians but also how they interact with their patients that is affected. Accumulating evidence indicates some of the potential risks of burnout (Table II).

Furthermore, burnout in the workplace has been described as being a contagious condition 38 which contributes to perpetuating the situation. It is essential to understand the factors that impact upon employee workplace stress and burnout so that initiatives with a potential positive effect can be developed reducing levels of stress and related negative outcomes.

\section{Managing burnout}

Burnout is complex and is unable to be treated by a specific intervention. Anti-depressive 
TABLE II.-The epidemiology of burnout: consequences of burnout.

Physician

- Lower levels of empathy 27

- Poor work performance, impaired decision making, selfreported suboptimal patient care 24

- Increased risk of medical errors 24

- Dissatisfied physicians and intention to leave 28

- Sleep disorders 25

- Increased cardiovascular risk 13

- Diabetes 29

- Obesity 30

- Impaired cognitive function 31

- Acceleration of the rate of biological aging 30

- Alcoholism and drug addiction 32

- Suicide ideation 33

- Accidents after a nightshift 28

- Conflict between family and professional life, interpersonal conflicts and marital problems 7,28

Patients

- Reduced adherence to treatment plans ${ }^{34}$

- Worsened clinical outcomes 34,35

- Lower patient satisfaction 34

Healthcare system

- Overuse of resources and thereby increased costs of care 20

- Reduced health outcomes 35

- Reduced productivity ${ }^{1,36}$

- Sick leave ${ }^{37}$

drugs and sleep inductors can be used when depression and sleep disturbances occur, but it is important to remember that these drugs do not resolve the problem.

There have been recent advances in the identification and characterization of stress-opposing neuromodulators such as endogenous opioids and their mechanisms. This could lead to a major advance in approaching the treatment of stress-related disorders. ${ }^{15}$ However, these studies have not advanced beyond the laboratory as of yet. Therefore, early detection and prevention of these problems as well as the promotion of wellbeing are essential.

\section{What can be done to alleviate burnout and improve wellbeing in anesthesiologists?}

The above question, posed by Nyssen et al. ${ }^{6}$ in 2003, is still relevant today. This subject has attracted a lot of attention and there are currently multiple studies in progress on how to prevent burnout and notice when physicians are at risk. The ability to provide quality care has been identified as the principal driver of physician satisfaction. ${ }^{39}$ There are currently no fixed measures to promote physician wellness but some efforts have been made to develop preventive strategies as well as therapies in physicians with burnout. Further studies are required specifically with anesthesiologists.

Both organizational and individual interventions need to be implemented to address the problem.

\section{Organizational strategies}

It is important to promote strategies that increase wellbeing in the workplace. Promoting a holistic care culture amongst workers could be a significant job resource in predicting job satisfaction. ${ }^{40}$ Healthcare centers have an economic stake in the wellbeing of the physicians, as when they are more satisfied they are generally more productive. ${ }^{41}$ Table III shows a summary of organizational strategies.

Beyond the clinical help required when physicians have difficulties, a support network is essential, ${ }^{44}$ not only when the problems occur but also when professionals need advice. It is important to perform a debriefing after critical events with the intention of constructive analysis and not to lay the blame on anyone. This is only possible with the existence of mentors who care about physician's wellbeing and consequently will aid in the prevention of burnout.

\section{Individual strategies}

As previously discussed, the individual response mechanisms to adverse events are a major determinant in the occurrence of burn-

TABLE III.-Organizational strategies.

Strategies for burnout prevention

- Reduce working hours and schedule flexibility 42

- Improve physician autonomy, job control and organizational justice 43

- Recognise physician value and opinion 44

- Measurement of physician satisfaction 44 and wellness 20

- Promote team work in small sized teams ${ }^{7}$

- Improve physician work environment 44

- Physician wellness and health promotion programs

- Development of non-technical skills to help physicians resolve conflicts and crises (communication, decisionmaking, teamwork and leadership) 44,45 
out. Several studies support the importance of promoting individual approaches in order to improve response to stressors and heighten wellbeing. Among these, there are specific strategies that could be implemented to achieve these goals, namely:

- encourage physicians to improve selfcare and maintain their health: in all phases of a medical career the best prevention from burnout is to encourage personal and professional health including physical, emotional, psychological and spiritual wellbeing. ${ }^{46}$ Physicians who take care of their health can transmit more credibility and motivation to their patients and residents 47 and this is particularly important in the context of anesthesia. A serious obstacle is that physicians frequently neglect their wellbeing and fail to seek help from others when advisable and anesthesiologists do not appear to be an exception. Other measures that are important in burnout prevention are the need for physical activity, ${ }^{48}$ physical relaxation (e.g. massage), ${ }^{49}$ healthy sleep, adequate rest and a healthy diet. 20,30 Further work-life balance factors are family and friends, ${ }^{8}$ and all of those mentioned should be taken good care of;

- encourage physicians towards a more engaging life and cultivate a sense of mastery, motivation and meaning in work with a positive attitude while nurturing a sense of calling; 50

- improve communication skills and encourage physicians to function as team members, helping to improve relationships with patients and colleagues and manage conflicts. Both communication and contact with colleagues are important in burnout prevention in anesthesiologists ${ }^{9}$ as is maintaining a connection with social support systems. ${ }^{51}$ Simulation centers where these skills can be trained are another resource to prepare and equip professionals;

— encourage the readiness to seek help; 52

- emotion regulation strategies in stress management and empathy: emotions are fundamental to judgement and decision making, even in clinical fields. Despite some studies having indicated that personal resources are not sufficient to counteract stress factors,, 53 in the last few years, emotion regulation strategies based on mindfulness, self-compassion and acceptance have been shown to be approaches with substantial supporting evidence for reducing burnout and for stress management in physicians. ${ }^{54,55}$ Emotional competencies such as mindfulness, self-compassion, resilience and empathy are predictors of wellbeing 53 and must be promoted in the medical community.

These strategies are important as they have the potential to promote the reinterpretation of stressors, confronting emotions through acceptance and attentional processes and developing more functional and effective ways of dealing with them without necessarily changing the stressor itself.

\section{Mindfulness}

Mindfulness is a self-regulation tool, introduced by Kabat-Zinn 56 in the 1980s for stress management in chronic pain patients. It stems from Buddhism and is a way of meditating to cultivate present moment awareness. Its goal is to disengage from strong attachment to beliefs, thoughts or emotions, thus developing a greater sense of emotional balance and wellbeing. 57 There is neuro-scientific evidence for changes in mental processes and underlying neural circuits that are involved in meditation. 58

Recently, it has been successfully implemented in areas such as physician stress management 58 and burnout, promoting wellbeing, improving empathy and increasing psychological resilience. 59 While the neuroscientific study of meditation is relatively new it has led to some promising findings that reveal how this approach may exert its effects and underscore the plasticity of the brain circuits that underlie complex regulatory mental functions.

\section{Self-compassion}

Self-compassion, is defined by being aware of and connected to one's own suffering, not avoiding it. ${ }^{60}$ It is composed of three components one of which is mindfulness. It has also been suggested that the relationship between 


\section{COPYRIGHT ${ }^{\odot} 2017$ EDIZIONI MINERVA MEDICA}

LAPA

BURNOUT SYNDROME AND EMOTION REGULATION

mindfulness and wellbeing is partially mediated by self-compassion. ${ }^{61}$ Compassion meditation is generally intended to cultivate both self-compassion and compassion towards others.

Self-compassion, has received a lot of attention recently as a means of cultivating resilience to stress, burnout and emotional exhaustion. ${ }^{54}$ Beyond this it has been suggested that self-compassion is associated with healthy relationship function, with its benefits being not only personal but also interpersonal. ${ }^{62}$ This potential in the interpersonal relationships of anesthesiologists should be further investigated.

\section{Resilience}

Resilience is the process of adapting to significant sources of stress or trauma. ${ }^{63}$ It is a complex and multi-dimensional phenomenon and has been defined as the ability of a person to recover, rebound, adjust or even thrive following misfortune, change or adversity. It has been identified as an essential condition of wellbeing in physicians 53 and has been associated with lower prevalence of posttraumatic stress disorder and burnout. ${ }^{64}$ With resilience the quality of care, caring and sustainability of the health care workforce can be improved. ${ }^{53}$

\section{Empathy}

Empathy is the ability to share or recognize emotions experienced by another person. ${ }^{65}$ Empathy in physicians may help them to benefit from more meaningful work, increased wellbeing and reduced symptoms of burnout 27 and has been linked with increased levels of patient satisfaction. Recent studies have concluded that during medical training empathy declines and that distress is a key determinant in this. ${ }^{66}$ To cultivate physician empathy it would be important to identify the exact reasons for empathy decline by making specific, evidence-based statements as well as developing targeted interventions.

Burnout is a multifactorial phenomenon, and it is possible that a multidimensional and holistic approach would be the most adequate.
Physicians should try to find the appropriate engagement strategies for themselves. More and more importance is being given to empathy, humanism, self-compassion, mindfulness and resilience but measurement and implementation of these competencies in the medical community continues to be a challenge. Adding stress management training, based on these competences, to the anesthesia education curriculum could help anesthesiologists to deal more successfully with stress. Further research is necessary to identify which programs of emotion regulation strategies will best suit the needs of anesthesiologists and to measure these effects on patient care and health care system.

\section{Wellbeing and high-quality healthcare}

The quality of care in healthcare organizations is usually assessed by the use of patientbased indicators and the wellbeing of physicians is rarely taken into account.

However, the importance of this is being recognized and it has been reported that satisfied physicians tend to be more committed to the work of organizations, increase productivity and decrease treatment costs as well. ${ }^{67}$

Furthermore, it has been observed that physician wellbeing contributes to patients' adherence to treatment and satisfaction. ${ }^{20}$ For this reason, healthcare centers have an economic stake in the wellbeing of the physicians, as when they are more satisfied they are generally more productive. ${ }^{41}$

Wellbeing is a prerequisite for good clinical practice which in turn leads to high quality healthcare. ${ }^{68}$ For this to happen, the wellness of all members of the team must be taken care of, meaning that all are working in the same direction towards patient needs.

Future work will need to address additional questions: How to improve motivation, empathy and happiness in anesthesiologists? How to measure wellbeing in anesthesiologists? Could mindfulness trait be a good quality indicator? Which meditation practices are best for physicians, and particularly for anesthesiologists? 


\section{COPYRIGHT ${ }^{\odot} 2017$ EDIZIONI MINERVA MEDICA}

\section{Conclusions}

Anesthesiologists face a wide variety of stressors all of which may result in stress, depression and burnout and can be detrimental to patient care and health care systems.

Preventing and detecting burnout early in its course is important and it is a priority to develop a wellbeing culture in anesthesiologists' personal and professional life. Interventions to address and prevent burnout must begin early in anesthesia medical training and strategies must be developed to decrease workload while maximizing autonomy. In addition, efforts should be made to empower anesthesiologists to build the knowledge and skills necessary to become competent physicians, as well as the emotional health to face the challenges inherent in medical practice.

Up to now, research in this area has not been controlled and based on small samples. This fact suggests the need for further studies, prospective, with a controlled design and a more rigorous methodology.

Future prospective research should use multiple methodologies (psychological, neurochemistry and neuroimaging) to understand emotion regulation and the importance of mindfulness and self-compassion in stress and burnout management. In this way, it will be possible to outline more efficient strategies for prevention and treatment of burnout and therefore promote wellbeing in anesthesiologists.

\section{Key messages}

- Burnout is a serious problem among anesthesiologists and this impacts seriously in their performance.

- New approaches like bringing awareness towards emotions and mindfulness techniques seem to be highly promising institutional as well as personal interventions are the essential components necessary to win the battle against burnout.

\section{References}

1. Maslach C, Schaufeli WB, Leiter MP. Job burnout. Ann Rev Psychol 2001;52:397-422.

2. Bianchi R, Schonfeld IS, Laurent E. Burnout-depression overlap: A review. Clin Psychol Rev 2015;36:28-41.

3. van der Wal RAB, Bucx MJL, Hendriks JCM, Scheffer G-J, Prins JB. Psychological distress, burnout and personality traits in Dutch anaesthesiologists. Eur J Anaesthesiol 2016;33:179-86.

4. Shanafelt TD, Hasan O, Dyrbye LN, Sinsky C, Satele D, Sloan J, et al. Changes in burnout and satisfaction with work-life balance in physicians and the general US working population between 2011 and 2014. Mayo Clin Proc 2015:90:1600-13.

5. Morais A, Maia P, Azevedo A, Amaral C, Tavares J. Stress and burnout among Portuguese anaesthesiologists. Eur J Anaesthesiol 2006;23:433-9.

6. Nyssen AS, Hansez I, Baele P, Lamy M, De Keyser V. Occupational stress and burnout in anaesthesia. $\mathrm{Br} \mathrm{J}$ Anaesth 2003;90:333-7.

7. Chiron B, Michinov E, Olivier-Chiron E, Laffon M, Rusch E. Job satisfaction, life satisfaction and burnout in French anaesthetists. J Health Psychol 2010;15:94858.

8. Jackson SH. The role of stress in anaesthetists' health and well-being. Acta Anaesthesiol Scand 1999;43:583-602.

9. Lederer W, Kinzl JF, Trefalt E, Traweger C, Benzer A. Significance of working conditions on burnout in anesthetists. Acta Anaesthesiol Scand 2006;50:58-63.

10. Lapa TA, Carvalho SA, Viana JS, Ferreira PL, PintoGouveia J. Stressors in anaesthesiology: development and validation of a new questionnaire: A cross-sectional study of Portuguese anaesthesiologists. Eur J Anaesthesiol 2016;33:807-15.

11. Nyssen A-S, Hansez I. Stress and burnout in anaesthesia. Curr Opin Anaesthesiol 2008;21:406-11.

12. Golkar A, Johansson E, Kasahara M, Osika W, Perski A, Savic I. The influence of work-related chronic stress on the regulation of emotion and on functional connectivity in the brain. PLoS One 2014;9:e104550.

13. Danhof-Pont MB, van Veen T, Zitman FG. Biomarkers in burnout: a systematic review. J Psychosom Res 2011;70:505-24.

14. Staub DR, Lunden JW, Cathel AM, Dolben EL, Kirby LG. Morphine history sensitizes postsynaptic GABA receptors on dorsal raphe serotonin neurons in a stress-induced relapse model in rats. Psychoneuroendocrinology 2012;37:859-70

15. Valentino RJ, Van Bockstaele E. Endogenous opioids: The downside of opposing stress. Neurobiol Stress 2015;1:23-32.

16. Kwok CHT, Devonshire IM, Bennett AJ, Hathway GJ. Postnatal maturation of endogenous opioid systems within the periaqueductal grey and spinal dorsal horn of the rat. Pain 2014;155:168-78.

17. Kepler KL, Standifer KM, Paul D, Kest B, Pasternak GW, Bodnar RJ. Gender effects and central opioid analgesia. Pain 1991;45:87-94.

18. Tei S, Becker C, Kawada R, Fujino J, Jankowski KF, Sugihara $\mathrm{G}$, et al. Can we predict burnout severity from empathy-related brain activity? Transl Psychiatry 2014;4:e393.

19. Kluger MT, Townend K, Laidlaw T. Job satisfaction, stress and burnout in Australian specialist anaesthetists. Anaesthesia 2003;58:339-45.

20. Wallace JE, Lemaire JB, Ghali WA. Physician wellness: a missing quality indicator. Lancet 2009;374:1714-21.

21. Schaufeli WB, Bakker AB, van der Heijden FMMA, Prins JT. Workaholism, burnout and well-being among 


\section{COPYRIGHT ${ }^{\odot} 2017$ EDIZIONI MINERVA MEDICA}

junior doctors: the mediating role of role conflict. Work \& Stress 2009;23:155-72.

22. El-Masry R, Shams T, Al-Wadani H. Anaesthetist-surgeon conflicts at the workplace: an exploratory singlecenter study from Egypt. Ibnosina J Med Biomed Sci 2013;5:148-56.

23. Blom V, Bergström G, Hallsten L, Bodin L, Svedberg P. Genetic susceptibility to burnout in a Swedish twin cohort. Eur J Epidemiol 2012;27:225-31.

24. De Oliveira GS, Chang R, Fitzgerald PC, Almeida MD, Castro-Alves LS, Ahmad S, et al. The prevalence of burnout and depression and their association with adherence to safety and practice standards: A survey of united states anesthesiology trainees. Anesth Analg 2013;117:182-93.

25. Lindfors PM, Nurmi KE, Meretoja OA, Luukkonen RA, Viljanen A-M, Leino TJ, et al. On-call stress among Finnish anaesthetists*. Anaesthesia 2006;61:856-66.

26. Shanafelt TD, Gradishar WJ, Kosty M, Satele D, Chew $\mathrm{H}$, Horn L, et al. Burnout and career satisfaction among US oncologists. J Clin Oncol 2014;32:678-86.

27. Thomas MR, Dyrbye LN, Huntington JL, Lawson KL, Novotny PJ, Sloan JA, et al. How do distress and wellbeing relate to medical student empathy? A multicenter study. J Gen Intern Med 2007;22:177-83.

28. Mion G, Libert N, Journois D. [Burnout-associated factors in anesthesia and intensive care medicine 2009 survey of the French Society of anesthesiology and intensive care]. Ann Fr Anesth Reanim 2013;32:175-88. [Article in French]

29. Melamed S, Shirom A, Toker S, Shapira I. Burnout and risk of type 2 diabetes: a prospective study of apparently healthy employed persons. Psychosom Med 2006;68:863-9.

30. Ahola K, Sirén I, Kivimäki M, Ripatti S, Aromaa A, Lönnqvist $\mathrm{J}$, et al. Work-related exhaustion and telomere length: a population-based study. PLoS One 2012;7:e40186.

31. Orena E, Caldiroli D, Cortellazzi P. Does the Maslach Burnout Inventory correlate with cognitive performance in anesthesia practitioners? A pilot study. Saudi J Anaesth 2013;7:277.

32. Weeks AM, Buckland MR, Morgan EB, Myles PS. Chemical dependence in anaesthetic registrars in Australia and New Zealand. Anaesth Intensive Care 1993;21:151-5.

33. Hawton K, Clements A, Sakarovitch C, Simkin S, Deeks JJ. Suicide in doctors: a study of risk according to gender, seniority and specialty in medical practitioners in England and Wales, 1979-1995. J Epidemiol Community Health 2001;55:296-300.

34. Shanafelt TD, Bradley KA, Wipf JE, Back AL. Burnout and self-reported patient care in an internal medicine residency program. Ann Intern Med 2002;136:358-67.

35. Welp A, Meier LL, Manser T. Emotional exhaustion and workload predict clinician-rated and objective patient safety. Front Psychol 2015;5:1573.

36. Hyman SA, Michaels DR, Berry JM, Schildcrout JS, Mercaldo ND, Weinger MB. Risk of burnout in perioperative clinicians: a survey study and literature review. Anesthesiology 2011;114:194-204.

37. Borritz M, Rugulies R, Christensen KB, Villadsen E, Kristensen TS. Burnout as a predictor of self-reported sickness absence among human service workers: prospective findings from three year follow up of the PUMA study. Occup Environ Med 2006;63:98-106.

38. Chan AOM, Huak CY. Influence of work environment on emotional health in a health care setting. Occup Med (Lond) 2004;54:207-12.

39. Friedberg MW, Chen PG, Van Busum KR, Aunon F, Pham C, Caloyeras JP, et al. Factors affecting physician professional satisfaction and their implications for patient care, health systems, and health policy. Santa Mon- ica, CA: RAND Corporation; 2013 [Internet]. Available from: www.rand.org/pubs/research reports/RR439.html [cited 2016, Dec 16]

40. Ng S-M, Fong TCT, Wang X-L. The role of holistic care culture in mitigating burnout and enhancing engagement A study among elderly service workers in Hong Kong Aging Ment Health 2011;15:712-9.

41. Baruch-Feldman C, Brondolo E, Ben-Dayan D, Schwartz J. Sources of social support and burnout, job satisfaction, and productivity. J Occup Health Psychol 2002;7:84-93.

42. Sussman D, Paul JE. The impact of transitioning from a 24-hour to a 16-hour call model amongst a cohort of Canadian anesthesia residents at McMaster University - a survey study. Adv Med Educ Pract 2015;6:501-6.

43. Lindfors PM, Heponiemi T, Meretoja OA, Leino TJ, Elovainio MJ. Mitigating on-call symptoms through organizational justice and job control: a cross-sectional study among Finnish anesthesiologists. Acta Anaesthesiol Scand 2009;53:1138-44.

44. Rama-Maceiras P, Parente S, Kranke P. Job satisfaction, stress and burnout in anaesthesia: relevant topics for anaesthesiologists and healthcare managers? Eur J Anaesthesiol 2012;29:311-9.

45. Flin R, Patey R, Glavin R, Maran N. Anaesthetists' nontechnical skills. Br J Anaesthesia 2010;105:38-44.

46. Spickard A, Gabbe SG, Christensen JF. Mid-career burnout in generalist and specialist physicians. JAMA 2002;288:1447-50

47. Frank E, Breyan J, Elon L. Physician disclosure of healthy personal behaviors improves credibility and ability to motivate. Arch Fam Med 2000;9:287-90.

48. Lindwall M, Gerber M, Jonsdottir IH, Börjesson M, Ahlborg G. The relationships of change in physical activity with change in depression, anxiety, and burnout: a longitudinal study of Swedish healthcare workers. Health Psychol 2014;33:1309-18.

49. Ruotsalainen JH, Verbeek JH, Mariné A, Serra C. Preventing occupational stress in healthcare workers. Cochrane Database Syst Rev 2015;(4):CD002892.

50. Yoon JD, Daley BM, Curlin FA. The association between a sense of calling and physician well-being: a national study of primary care physicians and psychiatrists. Acad Psychiatry 2016 Jan 25. [Epub ahead of print]

51. Myers DG. The funds, friends, and faith of happy people. Am Psychol 2000;55:56-67.

52. Worley LLM. Our fallen peers: A mandate for change. Acad Psychiatry 2008:32:8-12.

53. Zwack J, Schweitzer J. If every fifth physician is affected by burnout, what about the other four? Resilience strategies of experienced physicians. Acad Med 2013;88:382-9.

54. Raab K. Mindfulness, Self-Compassion, and Empathy Among Health Care Professionals: A Review of the Literature. J Health Care Chaplain 2014;20:95-108.

55. Regehr C, Glancy D, Pitts A, LeBlanc VR. Interventions to reduce the consequences of stress in physicians: a review and meta-analysis. J Nerv Ment Dis 2014;202:353-9.

56. Kabat-Zinn J. An outpatient program in behavioral medicine for chronic pain patients based on the practice of mindfulness meditation: theoretical considerations and preliminary results. Gen Hosp Psychiatry 1982;4:33-47.

57. Ludwig DS. Mindfulness in Medicine. JAMA 2008;300:1350.

58. Holzel BK, Lazar SW, Gard T, Schuman-Olivier Z, Vago DR, Ott U. How does mindfulness meditation work? Proposing mechanisms of action from a conceptual and neural perspective. Perspect Psychol Sci 2011;6:537-59.

59. Krasner MS, Epstein RM, Beckman H, Suchman AL, Chapman B, Mooney CJ, et al. Association of an educational program in mindful communication with burnout, empathy, and attitudes among primary care physicians. JAMA 2009;302:1284-93. 


\section{COPYRIGHT $^{\circledR} 2017$ EDIZIONI MINERVA MEDICA}

60. Neff KD. The development and validation of a scale to measure self-compassion. Self Identity 2003;2:22350 .

61. Hollis-Walker L, Colosimo K. Mindfulness, self-compassion, and happiness in non-meditators: A theoretical and empirical examination. Pers Individ Dif 2011;50:222-7.

62. Yarnell LM, Neff KD. Self-compassion, interpersonal conflict resolutions, and well-being. Self Identity 2012;12:146-59.

63. Windle G. What is resilience? A review and concept analysis. Rev Clin Gerontol 2011;21:152-69.

64. Mealer M, Jones J, Moss M. A qualitative study of resilience and posttraumatic stress disorder in United States ICU nurses. Intensive Care Med 2012;38:1445-51.
65. Gonzalez-Liencres C, Shamay-Tsoory SG, Brüne M. Towards a neuroscience of empathy: Ontogeny, phylogeny, brain mechanisms, context and psychopathology. Neurosci Biobehav Rev 2013;37:1537-48.

66. Neumann M, Edelhäuser F, Tauschel D, Fischer MR, Wirtz M, Woopen C, et al. Empathy decline and its reasons: a systematic review of studies with medical students and residents. Acad Med 2011;86:996-1009.

67. Judge TA, Thoresen CJ, Bono JE, Patton GK. The job satisfaction-job performance relationship: a qualitative and quantitative review. Psychol Bull 2001;127:376-407.

68. Bodenheimer T, Sinsky C. From triple to quadruple aim: care of the patient requires care of the provider. Ann Fam Med 2014;12:573-6.

Conflicts of interest.-The authors certify that there is no conflict of interest with any financial organization regarding the material discussed in the manuscript.

Article first published online: October 4, 2016. - Manuscript accepted: October 3, 2016. - Manuscript revised: September 1, 2016. Manuscript received: April 10, 2016. 